\title{
Toward a new generation of effective problem solvers and project-oriented applied ecologists
}

\author{
Corrado Battisti ${ }^{1,2}$, Giovanni Amori ${ }^{3}$, and Luca Luiselli ${ }^{4,5,6}$ \\ ${ }^{1}$ Torre Flavia LTER (Long Term Ecological Research) Station, Servizio Aree protette - parchi regionali, Città \\ Metropolitana di Roma Capitale, viale G. Ribotta, 41, 00144 Rome, Italy \\ ${ }^{2}$ Faculty of Science, University of Rome III, viale Marconi, 446, 00146 Rome, Italy \\ ${ }^{3}$ CNR-Research Institute on Terrestrial Ecosystem, via dell'Università, 32, 00185 Rome, Italy \\ ${ }^{4}$ IDECC - Institute for Development, Ecology, Conservation and Cooperation, \\ via G. Tomasi di Lampedusa 33, 00144 Rome, Italy \\ ${ }^{5}$ Department of Applied and Environmental Biology, Rivers State University of Science and Technology, \\ P.M.B. 5080, Port Harcourt, Nigeria \\ ${ }^{6}$ Département de Zoologie, Université de Lomé, Lomé, Togo \\ Correspondence: Corrado Battisti (c.battisti@ cittametropolitanaroma.gov.it)
}

Received: 23 January 2020 - Revised: 28 March 2020 - Accepted: 30 March 2020 - Published: 5 May 2020

\begin{abstract}
In an era of environmental crises, conservation and management strategies need a new generation of applied ecologists. Here, we stimulate the next-generation applied ecologists to acquire a pragmatic mentality of problems solvers in real contexts, using the wide arsenal of concepts, approaches and techniques available in the project management (PM) arena using a road map based on the main steps of conservation project cycle. The acquisition of the conceptual and operational framework of PM can allow the next-generation applied ecologists to take on a more important role in nature conservation strategies: from data samplers, analyzers and interpreters to suppliers of solutions and decisions driving changes in species' targets inhabiting real contexts. Since the high number of applied ecologists, this change in approach (from analytical to operational) could make the difference in conservation science. We also provided, as a conceptual framework, a set of suggestions and approaches useful to facilitate this change.
\end{abstract}

\section{Introduction}

You either have to be part of the solution, or you're going to be part of the problem. (E. Cleaver, Black Panther)

We carry out nature conservation and management strategies because we want to solve environmental problems, such as maintaining or improving our biodiversity targets or mitigating the anthropogenic threats (Soulé and Orians, 2001). Changing an unsatisfactory condition implies the need to act (theory of change; Mayne, 2015) by implementing a series of operational steps included in a project (i.e., in "any set of actions undertaken by a group of practitioners to achieve some defined objectives aimed to solve environmental problems"; Margoluis and Salafsky, 1998; Margoluis et al., 2009).
In this regard, project management (PM) is the disciplinary arena that is rich in approaches and that may represent a mine of opportunity for applied ecologists (e.g., Stoll-Kleemann, 2010). Any time applied ecologists work toward the mitigation or reduction of anthropogenic impacts on ecological targets, they should develop operational projects following the interdisciplinary logic of PM (Hockings, 2006).

Following a scientific logic, basic ecologists define a research problem focused on specific targets. Subsequently, they construct research hypotheses, set up sampling/experimental designs, carry out protocols, collect data and proceed to their analyses, discussing the results and their implications and obtaining evidence. In this way they achieve their research goals that will be published in scientific journals. However, in the Anthropocene, environmental prob- 
lems heavily interfere with the object of study of the ecologists (Johnson et al., 2017). Therefore, to carry out research on ecological targets is no longer possible without considering all the anthropogenic threats which interfere with them. Therefore, in recent decades, ecologists have also focused on the effects of human-induced threats (Salafsky et al., 2008; Battisti et al., 2019) and scientific papers have often concluded with sections entitled "implication for conservation", providing evidence-based suggestions aimed at promoting the operational strategies.

The role of applied ecologists as prompters of evidencebased strategies aimed at controlling human-induced threats is crucial. Nevertheless, very often the applied ecologists' work is not actually completely applied. To complete themselves as conservation managers, they must take an actionoriented role. They should be aware that problem solvers should not only collect data and provide recommendations, but also (i) identify the general problem (problem finding and setting); (ii) indicate achievable goals; (iii) suggest solutions; (iv) make decisions, by selecting which of the possible solutions could be the most effective; (v) start and coordinate working teams; (vi) monitor project effectiveness, choosing appropriate indicators and distinguishing between first-level results (so-called "outputs" in terms of works, activities and products) and second-level results (so-called outcomes on targets); (vii) adapt and improve the project; and (viii) communicate the results (Hockings, 2006).

Although each of these steps requires specific training, project-oriented ecologists must at least be aware of the logic of PM (Battisti, 2018). Therefore, it is necessary that the applied ecologists know many PM tools, making a change of perspective (i) from the data sampling, analysis and interpretation (ii) to providers of recommendations and implications and finally (iii) to problem solvers and project-oriented conservation managers having an active pragmatic role in operational strategies (Table 1).

Data collection and analyses are exciting for a basic scientist but should not be the ultimate goal for a problem-solver ecologist: in the PM language, data sampling without understanding when to stop them is called "analysis/paralysis" (i.e., an unhealthy obsession with numbers, analyses and reports; Langley, 1995), leading to a loss of time and procrastination. In conservation projects money is limited and time is scarce (a nonrenewable resource). Basic research, although fundamental, must be limited using time management approaches, so that other project steps can be started. Moreover, carrying out only basic research can greatly reduce the role of the ecologists, for example by excluding them from seeking solutions and making decisions that could be strategic for environmental targets. Furthermore, in crisis contexts, continuing to do basic research without taking responsibility for proposing and starting projects might not be in line with the conservation ethic. The research is not excluded from a project: a project-oriented research can intervene in several

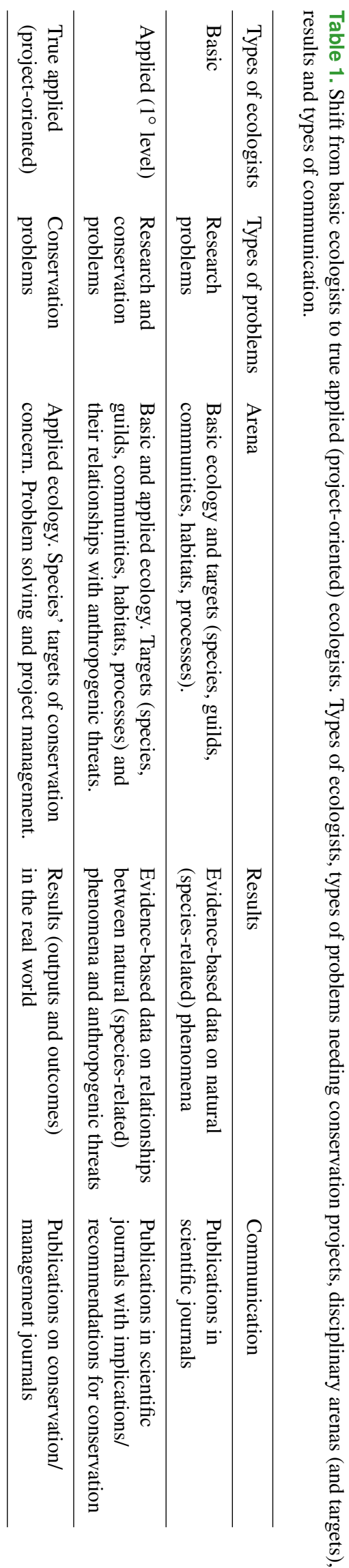




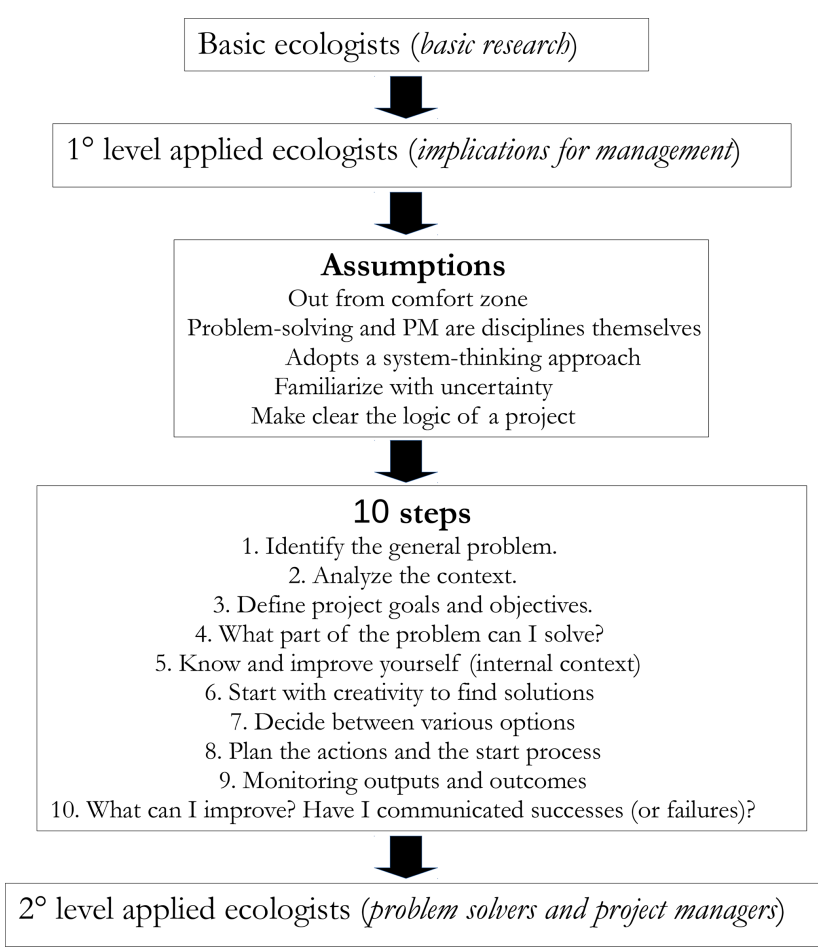

Figure 1. A framework explaining the proposed logic process starting from basic ecologists to $1^{\circ}$ level applied ecologists to $2^{\circ}$ level applied ecologists through five assumptions and 10 steps.

phases, still keeping well in mind that data will be only a tool useful to achieve the applied objectives.

Moving toward an operational approach is important because delegating the PM to experts belonging to other disciplines may not allow biodiversity conservation. Delegating to nonecologist managers the species' conservation can lead to the ineffectiveness (= failure) of the project itself. Last but not least, failure in projects can lead to cascade effects not only on our species' targets but also at the human dimension level (i.e., psycho-social level: sense of powerlessness, frustration and demotivation, cynicism). Who, if not an ecologist, can provide solutions, suggest actions and select specific indicators in circumstances where there is a conservation problem? The knowledge of the status, priorities and urgency regarding a species/community target comes from ecologists. They must enter the conservation control room.

In order to build a professional profile of project-based ecologists, issues related to the social and human dimension should not be underestimated: acquiring the logic of the project also means having the humility to acquire new management concepts, adopting a system-thinking approach, and becoming familiar with uncertainty and errors.

Here we reported a framework with five basic assumptions and 10 synthetic PM steps, exploring some issues (review in Battisti, 2018; Fig. 1) and adding operational examples from a case study (Battisti et al., 2019; Table 2).

\section{Adopting a project logic in five assumptions and 10 steps}

Assumption 1. Meetings among ecologists (e.g., in conferences) are exciting. However, ecologists who want to solve problems in real socioecological contexts must get out of their comfort zone: i.e., the psychological state in which things feel familiar to a researcher, so that they perceive a good control of their environment, experiencing low levels of stress (White, 2009). In a project the disciplinary competence and the social groups concerned are many and heterogeneous: therefore, ecologists should meet engineers, social and agriforest scientists, urban planners, policy makers, administrators and citizens. In this sense, a project-oriented ecologist must be flexible and transversal, be prepared to work in a complex socioecological system, and be prepared to deal with many different points of view. Therefore, a first suggestion for a project-oriented ecologists is open your mind, and free it from prejudices!

Assumption 2. A good ecologist, with a wonderful $\mathrm{H}$ index, is not automatically a conservation manager. The indepth knowledge of ecological targets is not synonymous with technical knowledge of how to search for solutions and make decisions about problems. An ecologist who wants to take action, following a technical-professional approach, should (i) follow a scientific approach (Guthery, 2007) and (ii) become familiar with the problem-solving and PM arenas. Problem solving and PM are not the sum of many disciplines but disciplines themselves. Therefore, be aware of facing a new field of knowledge. The PM arena is transdisciplinary (used in economic-financial, marketing, engineering, social and medical areas) and rich in opportunities that should be exploited by a new generation of applied ecologists.

Assumption 3. The complexity that characterizes the socioecological systems requires a conceptual approach based on system thinking (Cundill et al., 2012). Do not focus only on your targets. The world is much wider! Build causal chains and frameworks modeling the relationships among components (threats vs. targets) using concept and mind maps, causal loops, causal chains, and root-cause analysis (e.g., Margoluis et al., 2009).

Assumption 4. Familiarize yourself with uncertainty. Get ready to make mistakes (do not worry!). The complexity of socioecological systems exposes the projects to uncertainty often leading to forecast errors and surprises (Kay, 2008), which must be managed as opportunities, following an adaptive approach (McCarthy and Possingham, 2007), exploiting its value and gaining experience ("fail fast" approach). There are no unique recipes for success, because targets, conditions and circumstances are unique and their modeling is always incomplete, often with high uncertainty.

Assumption 5. Make clear the sequential logic of a project: context, planning and input (objectives, solutions, decisionmaking), process, monitoring (outputs, outcomes), adaptive 
Table 2. An example of project management practices (from Battisti et al., 2019) reported step by step (1-10).

\begin{tabular}{ll}
\hline Step & Example \\
\hline $\begin{array}{l}\text { Step 1. Identify the } \\
\text { general problem. }\end{array}$ & $\begin{array}{l}\text { When you carry out a research on shorebirds you observe that amount of anthropogenic marine/beach litter } \\
\text { (mostly plastic) is a general problem that could impact birds (Battisti et al., 2019). Therefore the general state- } \\
\text { ment of the problem could be "plastic litter on seashore could impact birds in my study area". }\end{array}$ \\
\hline $\begin{array}{l}\text { Step 2. Analyze the } \\
\text { context and identify the } \\
\text { specific problem. }\end{array}$ & $\begin{array}{l}\text { In our context, a specific type of plastic litter (the fishing lines with hooks) could impact breeding plovers } \\
\text { (Charadrius alexandrinus, included in Annex 147/2009/CE Dir., and C. dubius) in late spring and early summer } \\
\text { (April-June) in our study (and project) site. Therefore the threat is presented by "fishing lines (and hooks)" } \\
\text { while the targets are constituted by the two species of breeding plovers. Now the general problem (step 1) has } \\
\text { been specified as "fishing lines and hooks represent an impact on (adult and juvenile) breeding plovers occurring } \\
\text { from April to June in the coastal area X". }\end{array}$ \\
\hline $\begin{array}{l}\text { Step 3. Define an } \\
\text { overall project goal and } \\
\text { more specific objec- } \\
\text { tives. }\end{array}$ & $\begin{array}{l}\text { Project may be named "mitigating impact of fishing lines and hooks on breeding plovers". The general goal } \\
\text { could be "to mitigate the impact of fishing lines (and hooks) on breeding plovers in the X area during April- } \\
\text { June period". In our case, "the reduction of at least 80\% in length of the fishing lines (and hooks) abandoned, } \\
\text { impacting on breeding plovers by March 2022 in the Southern sector of the coastal site X" represents a correctly } \\
\text { declined (and therefore trackable) objective: indeed, it is specific (targets are plovers), measurable (the length } \\
\text { of the lines is a measurable parameter), achievable and realistic (changes can be obtained with a set of actions } \\
\text { distributed over time, considering the available resources), and referred to a limited and defined time range } \\
\text { (March 2022). "Increasing water birds", "eradicating alien species from the Po delta by 2020", "keeping constant } \\
\text { the density of the reed warblers in the reeds of Lake X" and "reducing the marine litter" are all objectives not } \\
\text { correctly declined (they are not SMART) because they lack at least one of the required attributes. They are not } \\
\text { achievable. }\end{array}$
\end{tabular}
achievable.

Step 4. Who could solve About the previous SMART objective, can I or a group of specialists reach it? Do we need operators, budget this problem? What part resources, technology and organizations? Start simulating a real pilot project. Through context analysis, you of the problem can I should have gotten an idea of the amount of fishing lines and hooks and the number of breeding pairs of plovers, solve? as well as the area involved. What part of the problem could you solve alone or with a small group? If you cannot get public organizations or associations involved, consider Ashby's law and redefine the goal.

Step 5. Know and improve yourself. Open yourself to the real world. Analyze the internal context.

The removal of the fishing lines (and hooks) from the project site requires the involvement of a dozen operators. Students and teachers from a high school and some university students could be involved. They will constitute the project team (PT). According to the SWOT (strengths, weaknesses, opportunities, and threats) analysis, strengths are the motivation of the PT, a large number of operators, and the amount of resources provided by the high school and university; weaknesses are poor skills, competition among operators and cynicism of some students towards the project; opportunities are the possibility of communicating the problem to a wider public, concomitant registration of biological findings (e.g., psammophilous plants, molluscs) during the removal of the fishing lines and hooks, training of specialized operators, and increased awareness in students; and, finally, threats are that some beach resorts oppose the project and that the fishing lobby sees the project as a threat to their activity. To make the PT resilient and reduce the threats to the project highlighted in the SWOT analysis, fishermen and beach users will be involved, and it will be communicated how the fishermen's lobby collaborates to clean the beach from a threat that concerns everyone (even children who are hurt by the hooks). The threat has now become an opportunity.

Step 6. It stimulates creativity to find solutions (even provocative).

Step 7. Decide between various options.

Step 8. Plan the actions and the start process.

Step 9. Did we carry out the planned works, activities and products (monitoring of firstlevel results: outputs)? Did we get the expected results on our environmental targets (monitoring of secondlevel results: outcomes)?

Step 10. What did not go as planned? How can I improve? Have I communicated a problem, a project and successes (or failures)?
The $80 \%$ reduction of fishing lines (and hooks) from a beach can be obtained by communicating (and making aware) the problem to the fishermen, involving students which collect (with many different equipment/protocols) the litter on the beach, talking to the shops that sell products for fishermen, monitoring the sites and communicating the problem via social media. The fishermen themselves can propose innovative creative solutions.

Among the various solutions selected according to the techniques presented there is the direct removal of fishing lines (and hooks) from the beach, the division into sectors and the communication of the problem at fishing shops.

The actions (removal, communication, etc.) are scheduled in time, assigning the necessary roles and resources to the operators and taking into account the deadline (March 2022). In the process phase, students and other operators carry out actions aimed at removing fishing lines (and hooks) and at communicating the problems to fishermen.

Outputs: did we take the required actions? How many days? How many fishing lines (and hooks) have we removed? How many resources have we consumed? What surface of sandy beach did we reclaim? Outcomes: how many plovers (adults, juveniles and nests) have I protected? How effective was it even considering the comparison before and after the project and with other control areas (where the reclamation was not carried out)?

Check what did you do wrongly during the project in terms of PT, resources and decisions made. We may have chosen the wrong timing and approach or encountered specific circumstances that were not foreseen. Finally, in our study area, the project can be communicated via mass media, via social media, and locally to schools and other institutions. Scientific publications can also be written. In addition to the beneficial effects on plovers, to reach as many social strata as possible it may be necessary to communicate that also the beach users (and children) have benefited from the removal of the fishing lines (and hooks). 
management. A lot of opportunities to grow professionally will be available (Hockings, 2006).

After the assumptions, the following 10 step could complete the framework.

Step 1. Identify the general problem. Conceptualize and put into practice problem solving with a case study, even if simple (for example, in a "km-0 context" you frequent). What is the general problem you would like to solve? What is the criticality (e.g., the threat) that you would like to mitigate? At this stage the problem is identified only generally (no evidence has yet been gathered).

Step 2. Analyze the context and identify the specific problem. The context analysis is used to collect all the information useful to solve it, defining the problem in a more specific way. The better you define the problem, the more likely it is to be solved. Therefore, you should define the targets (their status and criticality), specifying which threats locally impact them (Salafsky et al., 2008).

Step 3. Define an overall project goal and more specific objectives. Name the project and indicate a general purpose. The assignment of a clear and synthetic name is important in communicating the problem to a wider audience. Moreover, you should define pragmatic objectives considering the available resources and the local conditions/circumstances/constraints (environmental, political, social, etc.).

Step 4. Who could solve this problem? What part of the problem can I solve? This is a decisive step to understand if the problem is within the range of skills and resource availability of a few ecologists, or if it is necessary to involve further professionals, stakeholders and citizens. It is rare that a project can be done alone; nevertheless, small groups can do great things. Therefore, activate (or simulate) the establishment of a project team (PT). What part of the problem is solvable and which professional figures can theoretically be involved with the available resources? Following Ashby's law, a problem is much too large compared to available resources in the following cases: (i) the problem is reduced in its complexity or (ii) resources involved to solve it have increased. This is a useful exercise to understand the gap between desirability and feasibility of an environmental change. However, be aware that there are not only the big-money projects. There may be local needs for changing the status of ecological targets even near your place! You can start simulating a pilot project with a real experiment (e.g., through role playing).

Step 5. Know and improve yourself. Analyze the internal context. PM requires a multidisciplinary approach: a project can be articulated involving many different disciplines and sociocultural targets. This requires a constructive and proactive approach; a great openness; and a good attitude to confrontation, listening, curiosity and empathy. Avoid cognitive bias (Kahneman and Lovallo, 1993), epistemic arrogance and nonconstructive behaviors (prejudice, negativity; Battisti, 2018). Since it will always be necessary to work in a team, it will be necessary to spend time through an internal context analysis, identifying strengths and weaknesses of the group and controlling group dynamics. For example, the SWOT analysis (Hill and Westbrook, 1997) is a technique that allows us to analyze strengths and weaknesses of the PT and the opportunities and threats on/against the project. In this regard, a facilitator may be needed. To establish a PT effective over time (therefore resilient, able to recover from a crisis during the project period) it is necessary to increase cognitive diversity (you should avoid building a team with only ecologists), involving both technical-scientific experts and local "wise people" (Intezari and Pauleen, 2018). Different points of view will facilitate the emergence of solutions rather than monodisciplinary groups. Moreover, you should improve the professional redundancy and technical flexibility inside the PT (Shin et al., 2012).

Step 6. Start with creativity to find solutions (even provocative). There are many possible solutions to a problem. The comparison with different world views stimulates creativity, which is useful for finding solutions. Some of these attitudes can be innate; however, creativity techniques (used in the engineering, medical, economic and marketing fields but little used by ecologists) can also be learned (e.g., through brainstorming, brain writing, divergent and lateral thinking; Aslan et al., 2014). Getting a solution (mitigation of a threat, restoring of a new habitat), with the few resources needed and taking into account the constraints, requires an effort of creativity (a term mistakenly assigned only to the artistic field). Thanks to their local expertise, a hydraulic engineer can provide a solution to the creation of a new habitat for a rare wetland bird or a fish farmer (belonging to the wise people) who knows the site history can suggest a solution for river restoration, since it know seasonality of local human activities, and so on.

Step 7. Decide between various options. Of the many solutions only one or a few will be selected (decision-making process; convergent thinking; Basadur and Hausdorf, 1996). Cost-benefit analysis, risk analysis and multicriteria approaches carried out for each option can direct the decision makers (Battisti, 2018).

Step 8. Plan the actions and the start process. Once the most suitable option has been chosen, actions must be defined to obtain the results. Schedule times, roles and responsibilities, and resources committed (budget, operators, materials, technology), and, finally, start with the operational phase. Efficiency must be guaranteed to meet deadlines and the methods indicated in the planning. Be careful with time thieves, and do not procrastinate!

Step 9. Did we carry out the planned works, activities and products (first-level results: outputs)? Did we get the expected results on our environmental targets (second-level results: outcomes)? The results in terms of actions represent the first level of monitoring. The results in terms of effects on targets represent the second level of monitoring (McDonaldMadden et al., 2011). The indicators necessary to verify the 
effectiveness of the project at this level will have been chosen in advance. The arsenal of PM is rich in suggestions for carrying out opportune sampling designs and a logic to select appropriate indicators: see the BACI (before-after controlimpact) design that allows a monitoring focused on the effect before and after a threat or project compared to control sites (Bro et al., 2004) and the DPSIR (driving forces-pressurestate-impact-response) that is useful to select indicators for different processes and factors (Kimmel et al., 2010).

Step 10. What did not go as planned? How can I improve? Have I communicated successes (or failures)? In complex socioecological systems, many expected results will not be achieved due to errors in design scenarios or during the operational actions. In this sense the only predictable thing about a project is that errors will be made. The project should be itself monitored through an adaptive approach (Margoluis et al., 2009).

Finally, all projects should end with the same communication actions. Successes (and failures) must be communicated in different ways (social media, publications) to make the experience and lessons learned shared.

\section{Concluding remarks}

Regardless of whether you are already a professional, or whether you do not have the possibility of joining work groups, the acquisition of the PM logic can make the ecologist grow, which can contribute to the identification of solutions to conservation problems. The tools available are many, and it is important to know them and master them. For example an applied ecologist who knows

- the SMART requisites (Bjerke and Renger, 2017) can clearly define a clear objective (specific, measurable, achievable, realistic and defined over time), so that the results can be monitored;

- the SWOT analysis (Hill and Westbrook, 1997) will analyze in advance all the points of strength and weaknesses in a PT and opportunities and threats affecting a project (thus becoming more pragmatic and resilient);

- the BACI (before-after control-impact) protocol (Bro et al., 2004) will be able to carry out a monitoring of effectiveness in a project area (i.e., the impact site), comparing it with a control area (without project), before and after the actions;

- the brainstorming techniques and creativity stimulation (Aslan et al., 2014) will be able to work in planning phase, with a group of operators developing original questions and ideas, obtaining nontrivial or prejudicial solutions to complex problems (the manual of absolute solutions does not exist!). Solutions each have strengths and weaknesses and a list both of costs and benefits: through the knowledge of the decision-making techniques one can analytically balance the different options avoiding biased solutions (heuristics), prejudices, dogma and conformism;

- the techniques of conflict resolution could be effective in solving complex situations with a win-win approach (Hirsch et al., 2011) through a negotiation that satisfies the parties (for example, between economic needs of a commercial activity and a conservation target);

- the DPSIR indicator system (Kimmel et al., 2010), in the monitoring phase, could help to identify logically which indicators to choose and quantify (indicators of pressure, impact, status, or response?), providing indications very useful to public administrators who plan a territory.

An applied ecologist with managerial skills could define which actions should be carried out to preserve a declining species, defining times, methods, roles and resources. These skills cannot only be the prerogative of other professionals.

There is nothing sadder than to see ecologists who are well prepared and aware of a crisis and that do not have the conceptual tools to operate and solve those problems. Therefore it is necessary to overcome the image of the ecologist who finds himself displaced in the face of an environmental problem, emotionally and uncritically proposing, without a design logic. It is necessary to build a generation of advanced ecologists as problem solvers, aware of the logic of project managers that (involved or not in real projects) know how to identify real problems, ask questions, and find cause-effect relationships, analyzing the context, finding solutions using creative tools and identifying the best alternatives.

Even without being involved in real conservation projects (i.e., without being professional managers), these projectoriented scientists should be able to talk head-on with a problem-solver mentality aimed at driving a change and moving away from a fine-grained specialization. Beyond the PM theory, the advice is to start immediately choosing a small and local environmental problem and making a simple pilot project (or even a mind experiment). This allows us to become familiar with mistakes (useful for learning!) as well as with objectives, solutions, decisions, actions, and indicators, applying one or more tools of the PM arsenal.

Pilot project process can be focused on specific local problems. Even if the change will be limited to a local context, this can lead to an operational awareness. The conservation of our targets will depend on how we applied ecologists know how to think and act as project managers, being aware of what it means to solve problems through action-oriented approaches.

Data availability. No data sets were used in this article. 
Author contributions. All authors contributed critically to the drafts and gave final approval for publication.

Competing interests. The authors declare that they have no conflict of interest.

Acknowledgements. A large number of colleagues, operators and citizen provided ideas, suggestions and criticism on this topic. Alex Zocchi largely improved the English language and style. A reviewer (Maria Amélia Martins-Loução) and the editor in chief (Daniel Montesinos) largely improved the first draft of the manuscript with useful comments and suggestions.

Review statement. This paper was edited by Daniel Montesinos and reviewed by Maria Amélia Martins-Loução.

\section{References}

Aslan, C. E., Pinsky, M. L., Ryan, M. E., Souther, S., and Terrell, K.: Cultivating creativity in conservation science. Conserv. Biol., 28, 345-353, 2014.

Basadur, M. and Hausdorf, P.A.: Measuring divergent thinking attitudes related to creative problem solving and innovation management, Creativ. Res. J., 9, 21-32, 1996.

Battisti, C.: Unifying the trans-disciplinary arsenal of project management tools in a single logical framework: Further suggestion for IUCN project cycle development, J. Nat. Conserv., 41, 63-72, 2018.

Battisti, C., Kroha, S., Kozhuharova, E., De Michelis, S., Fanelli, G., Poeta, G., Pietrelli, L., and Cerfolli, F.: Fishing lines and fish hooks as neglected marine litter: first data on chemical composition, densities, and biological entrapment from a Mediterranean beach, Environ. Sci. Pollut. Res., 26, 1000-1007, 2019.

Bjerke, M. B. and Renger, R.: Being smart about writing SMART objectives, Eval. Program Plann., 61, 125-127, 2017.

Bro, E., Mayot, P., Corda, E. V. E., and Reitz, F.: Impact of habitat management on grey partridge populations: assessing wildlife cover using a multisite BACI experiment, J. Appl. Ecol., 41, 846857,2004

Cundill, G., Cumming, G. S., Biggs, D., and Fabricius, C.: Soft systems thinking and social learning for adaptive management, Conserv. Biol., 26, 13-20, 2012.

Guthery, F. S.: Deductive and inductive methods of accumulating reliable knowledge in wildlife science, J. Wildlife Manage., 71, 222-225, 2007.

Hill, T. and Westbrook, R.: SWOT analysis: it's time for a product recall, Long Range Plann., 30, 46-52, 1997.

Hirsch, P. D., Adams, W. M., Brosius, J. P., Zia, A., Bariola, N., and Dammert, J. L.: Acknowledging conservation trade-offs and embracing complexity, Conserv. Biol., 25, 259-264, 2011.
Hockings, M.: Evaluating Effectiveness: A framework for assessing management effectiveness of protected areas, IUCN, Gland, Switzerland, 2006.

Intezari, A. and Pauleen, D. J.: Conceptualizing Wise Management Decision-Making: A Grounded Theory Approach, Decision Sci., 49, 335-400, 2018.

Johnson, C. N., Balmford, A., Brook, B. W., Buettel, J. C., Galetti, M., Guangchun, L., and Wilmshurst, J. M.: Biodiversity losses and conservation responses in the Anthropocene, Science, 356, 270-275, 2017.

Kahnemann, D. and Lovallo, D.: Timid choices and bold forecasts: A cognitive perspective on risk taking, Manage. Sci., 39, 17-31, 1993.

Kay, J.: The ecosystem approach: complexity, uncertainty, and managing for sustainability, Columbia University Press, New York, 2008.

Kimmel, K., Kull, A., Salm, J. O., and Mander, Ü.: The status, conservation and sustainable use of Estonian wetlands, Wetl. Ecol. Manag., 18, 375-395, 2010.

Langley, A.: Between "paralysis by analysis" and "extinction by instinct", Sloan Manage. Rev., 36, 63, 1995.

Margoluis, R. and Salafsky, N.: Measures of success: designing, managing, and monitoring conservation and development projects, Island Press, Washington, DC, 1998.

Margoluis, R., Stem, C., Salafsky, N., and Brown, M.: Using conceptual models as a planning and evaluation tool in conservation, Eval. Program Plann., 32, 138-147, 2009.

Mayne, J.: Useful theory of change models, Can. J. Program Eval., 30, 119-142, 2015.

McCarthy, M. A. and Possingham, H. P.: Active adaptive management for conservation, Conserv. Biol., 21, 956-963, 2007.

McDonald-Madden, E., Baxter, P. W., Fuller, R. A., Martin, T. G., Game, E. T., Montambault, J., and Possingham, H. P.: Should we implement monitoring or research for conservation?, Trend. Ecol. Evolut., 26, 108-109, 2011.

Salafsky, N., Salzer, D., Stattersfield, A. J., Hilton-Taylor, C., Neugarten, R., Butchart, S. H. M., Collen, B., Cox, N., Master, L. L., O'Connor, S., and Wilkie, D.: A standard lexicon for biodiversity conservation: unified classifications of threats and actions, Conserv. Biol., 22, 897-911, 2008.

Shin, S. J., Kim, T. Y., Lee, J. Y., and Bian, L.: Cognitive team diversity and individual team member creativity: A cross-level interaction, Acad. Manage. J., 55, 197-212, 2012.

Soulé, M. E. and Orians, G. (Eds.): Conservation biology: research priorities for the next decade, Island Press, Washington (DC), 2001.

Stoll-Kleemann, S.: Evaluation of management effectiveness in protected areas: methodologies and results, Basic Appl. Ecol., 11, 377-382, 2010.

White, A.: From Confort zone to Performance Management: understanding development and performance, White and McLean Publishing, La Houlette, Belgium, 2009. 